\title{
Proposed Novel Multiphase-Multilevel Inverter Configuration for Open-End Winding Loads
}

\author{
Sanjeevikumar Padmanaban ${ }^{\mathrm{a}}$, Patrick Wheeler ${ }^{\mathrm{b}}$, Frede Blaabjerg ${ }^{\mathrm{c}}$, Ahmet H.Ertas ${ }^{\mathrm{d}}$, \\ Joseph Olorunfemi Ojo ${ }^{\text {e,f }}$, Pawel Szcześniak ${ }^{\mathrm{g}}$ \\ a,* Ohm Technologies, Research and Development, Chennai-600 122, India. \\ ${ }^{\mathrm{b}}$ Power Electronics, Machines and Control (PEMC) Group, Department of Electrical \& \\ Electronics Engineering, Nottingham University, NG7 2RD-Nottingham, United Kingdom. \\ ${ }^{\mathrm{c}}$ Center of Reliable Power Electronics (CORPE), Department of Energy Technology, Aalborg \\ University, 9220-Aalborg, Denmark. \\ ${ }^{\mathrm{d}}$ Department of Biomedical Engineering, Engineering Faculty, Karabuk University \\ Baliklar Kayasi Mevkii, 78050 Karabuk, Turkey. \\ ${ }^{\mathrm{e}}$ Center for Energy System Research, Department of Electrical \& Computer Engineering, \\ Tennessee Technological University, Cookeville, 38505-Tennessee, United State of America. \\ ${ }^{\mathrm{f}}$ Eskom Centre of Excellence in HVDC Engineering, University of KwaZulu-Natal, \\ Durban, South Africa \\ ${ }^{\mathrm{g}}$ Institute of Electrical Engineering, University of Zielona Góra, Licealna 9, 65417-Zielona Góra, Poland. \\ Tel.: +91-98431-08228 \\ *E-Mail: sanjeevi_12@yahoo.co.in
}

\section{Keywords}

Dual three-phase inverter, six-phase inverter, multilevel inverters, multiphase drives, asymmetrical inverters, multiple space vectors, pulse-width modulation.

\begin{abstract}
This article address a new multiphase-multilevel inverter configuration for open-winding loads and suitable for medium power (low-voltage/high-current) applications such as 'More Electric Aircraft'. Modular structure comprised of standard dual three-phase voltage source inverter (VSI) along with one additional bi-directional semi-conductor device (MOSFET/IGBT) per phase and two capacitors with neutral point. The additional switches and capacitors are introduced to generate the additional voltage levels in outputs of the VSI. An original modified single carrier five-level modulation (MSCFM) algorithm is developed in this work and overcomes the complexity of standard space vector modulations, easy for real implementation purposes in digital processors. Proposed six-phase multilevel inverter configuration generates multilevel outputs with benefit in comprises with standard multilevel inverter topologies. Further, the complete numerical model of the proposed AC converter along with pulse-width modulation (PWM) is developed with Matlab/PLECS simulation software's. A set of observed results is presented in balanced working condition and always shown good agreement with the theoretical developments.
\end{abstract}

\section{Introduction}

The past 30 years of technological advancement in multi-phase AC drives proved that they are prominent solution than the classical three-phase AC drive versions [1-5]. Advantage includes the reliability, redundant configuration, reduced DC link ripple, increased power density, fault tolerability, and reduced per-phase of inverter rating [6-7]. Furthermore, the load power is split into multiple phases; hence Voltage Source Inverters (VSIs) will be constructed with limited power and current rating semiconductor switching devices (MOSFET/IGBT) [1-2,8]. The multiple three-phase VSIs are still attractive in framing multiphase $\mathrm{AC}$ drives, such as dual-, triple- and quadruple three-phase AC drives 


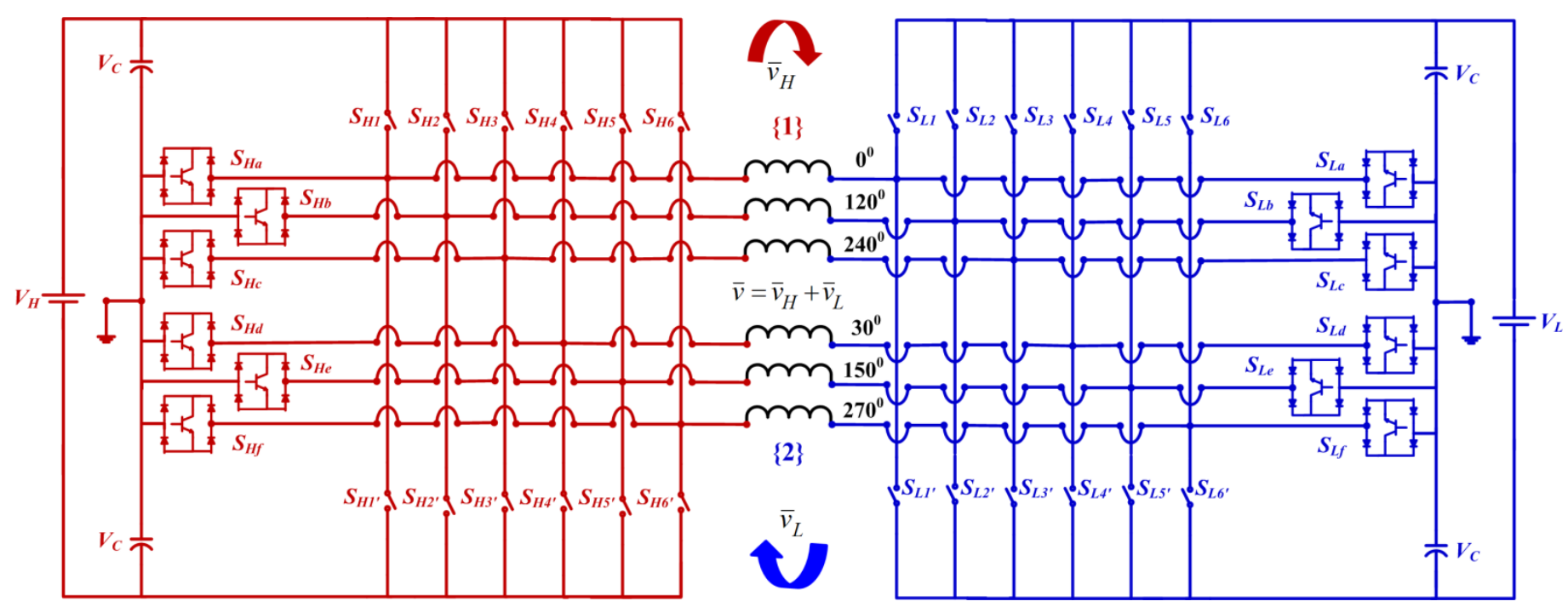

Fig. 1: Proposed schematic circuit of dual three-phase (asymmetrical) multilevel inverter with openwinding configuration.

as developed and employed in several applications [8-10]. Moreover, inherent redundant structure, multiphase AC drives are suited for critical applications in 'More Electric Aircraft' (MEA), where they replace the conventional hydraulic and pneumatic actuators and hence the entire aeronautic propulsion system will be improved [11-12]. In particular multiphase AC drives employed as motor for starting and act as a generator during flight. Multi-phase AC drives configuration, the six-phase ones are the foremost choice for medium power (low-voltage/high-current) applications for MEA [13]. By configuring two adjacent phases are arbitrarily shifted by $60^{\circ}$ (symmetrical type) [14-18] or by $30^{\circ}$ (asymmetrical or dual three-phase type) [3-4, 6, 8-10].

Further, classical VSIs can also generate multilevel stepped voltages at the output phases in addition to multiphase structures, by properly arranging the multiple VSIs configuration [3-4, 6, 8-10, 18-20]. Standard solution such cases is the three-phase dual inverters, restructured from H-bridge cascaded inverters by slight rearrangement of the DC sources. Hence, the three-phase VSI (two-level) are connected at the two ends of open-windings, and to obtain the differences of two single inverter's leg potential as output voltages [8-10, 18-21]. Benefits include, switching frequency and DC bus requirements are halved by half and moreover, two different potential sources can be utilized (photovoltaic/fuel-cell). Further, commonmode currents are limited by the PWM modulation techniques or by configuring with isolated DC sources [8-10, 14-20]. Such topologies are addressed with z-source impedance network in the DC link for a buck/boost the output voltages with limited common-mode components and standard dual inverters for grid integration with/without isolation transformer [18-20]. But still issues to be addressed by the dual inverters are having restricted levels in the output voltages, each leg are limited to three-levels and the output voltages appear in nine levels and cannot be overcome with addressing above topologies [3$4,6,8-10,18-20]$.

Considering above facts, this work articulates a novel configuration for dual three-phase asymmetrical $\left(30^{0}\right.$ arbitrary phase displacement between windings) multilevel inverter fit for open-winding, medium power (low-voltage/high-current) and MEA applications as shown in Fig. 1. Modular power circuit comprised of two classical six-phase voltage source inverters (VSIs) with additional bi-directional (IGBT) switch per phase and each one is connected across the open-end windings [21, 23-25]. Two capacitors are incorporated with the neutral connection either side of dual three-phase inverters, therefore, introduces the additional voltage levels in the outputs, i.e. 5-level in each leg phases [21]. Also, this article paper developed an original modified single carrier five-level modulation (MSCFM) scheme (independent modulation) and overcome the complexity for easy implementation with real digital processors. Proposed multiphase- multilevel inverter configuration can generate 5-level stepped output voltages by the each single VSI in compromised benefit of standard multilevel inverters with reliability [21-25]. To verify the performances, the complete numerical model multiphase converter 
system with MSCFM PWM algorithm is developed Matlab/PLECs simulation software's. Preliminary simulation results are presented in the paper version to show the reliability of the converter in symmetrical operating conditions and shown always a close conformity with a theoretical background.

\section{Split-phase decomposition space vector transformation for six-phase system}

A. Multiple space vector transformation

Complete six-phase system can be represented by space vector transformations to introduce as dual three-phase windings supplied by two insulated dual three-phase VSIs. Classically space vector transformation of an asymmetric six-phase system is represented by multiple space vectors as given below $[3,10,14]$ :

$$
\left\{\begin{array}{l}
\bar{x}_{1}=\frac{1}{3}\left[x_{1}+x_{2} \alpha^{4}+x_{3} \alpha^{8}+x_{4} \alpha+x_{5} \alpha^{5}+x_{6} \alpha^{9}\right] \\
\bar{x}_{3}=\frac{1}{3}\left[\left(x_{1}+x_{2}+x_{3}\right)+j\left(x_{4}+x_{5}+x_{6}\right)\right] \\
\bar{x}_{5}=\frac{1}{3}\left[x_{1}+x_{2} \alpha^{8}+x_{3} \alpha^{4}+x_{4} \alpha^{5}+x_{5} \alpha+x_{6} \alpha^{9}\right]
\end{array}\right.
$$

To be noted $\alpha=\exp (j \pi / 6)$, spatial displacement between windings [10].

The multiple space vectors $\bar{x}_{1}, \bar{x}_{3}$ and $\bar{x}_{5}$ are exposed in the sub-zones called $d_{1}-q_{1}, d_{3}-q_{3}$, and $d_{5}-q_{5}$ respectively. The six-phase system can be split into two three-phase sub-systems $\{1\}$ and $\{2\}$ accordingly to:

$$
\{1\}\left\{\begin{array}{l}
x_{1}^{(1)}=x_{1} \\
x_{2}^{(1)}=x_{2} \\
x_{3}^{(1)}=x_{3}
\end{array}, \quad\{2\}\left\{\begin{array}{l}
x_{1}^{(2)}=x_{4} \\
x_{2}^{(2)}=x_{5} \\
x_{3}^{(2)}=x_{6}
\end{array}\right.\right.
$$

The rotating arbitrary space vectors $\bar{x}^{(1)}, \bar{x}^{(2)}$ and the zero-sequence components $x_{0}^{(1)}, x_{0}^{(2)}$ can be defined for each three-phase sub-system $\{1\}$ and $\{2\}$, described as:

$$
\{1\}-\left\{\begin{array}{l}
\bar{x}^{(1)}=\frac{2}{3}\left[x_{1}^{(1)}+x_{2}^{(1)} \alpha^{4}+x_{3}^{(1)} \alpha^{8}\right] \\
x_{0}^{(1)}=\frac{1}{3}\left[x_{1}^{(1)}+x_{2}^{(1)}+x_{3}^{(1)}\right]
\end{array} ;\{2\}-\left\{\begin{array}{l}
\bar{x}^{(2)}=\frac{2}{3}\left[x_{1}^{(2)}+x_{2}^{(2)} \alpha^{4}+x_{3}^{(2)} \alpha^{8}\right] \\
x_{0}^{(2)}=\frac{1}{3}\left[x_{1}^{(2)}+x_{2}^{(2)}+x_{3}^{(2)}\right]
\end{array} .\right.\right.
$$

Now the relationships between multiple space vectors and split-phase space vectors are related by introducing Eq. 2 and Eq. 3 in Eq. 1 and expressed as below:

$$
\begin{gathered}
\left\{\begin{array}{l}
\bar{x}_{1}=\frac{1}{2}\left[\bar{x}^{(1)}+\alpha \bar{x}^{(2)}\right] \\
\bar{x}_{5}^{*}=\frac{1}{2}\left[\bar{x}^{(1)}-\alpha \bar{x}^{(2)}\right] . \\
\bar{x}_{3}=x_{0}^{(1)}+j x_{0}^{(2)}
\end{array}\right. \\
\left\{\begin{array}{l}
\bar{x}^{(1)}=\bar{x}_{1}+\bar{x}_{5}^{*} \\
x_{0}^{(1)}=\bar{x}_{3} \cdot 1
\end{array}, \quad\left\{\begin{array}{l}
\bar{x}^{(2)}=\alpha^{-1}\left(\bar{x}_{1}-\bar{x}_{5}^{*}\right) \\
x_{0}^{(2)}=\bar{x}_{3} \cdot j
\end{array} .\right.\right.
\end{gathered}
$$

Where the symbols “*” and "."denote complex conjugate and scalar (dot) product, respectively. 


\section{Dual three-phase inverter single carrier based five-level modulation algorithm}

The total power $P$ of the dual three-phase inverter can expressed as the sum of the power of the two inverters $\mathrm{H}$ and $\mathrm{L}[7-8]$ :

$$
\begin{gathered}
P=P_{H}+P_{L}=3 \bar{v} \cdot \bar{i} \\
P=P_{H}+P_{L}=\frac{3}{2}\left[\left(\bar{v}_{H}+\bar{v}_{L}\right) \cdot \bar{i}\right]
\end{gathered}
$$

If the bi-directional switch per phase and two capacitors with neutral are neglected in the Fig. 1, the resultant circuit is standard two-level six-phase inverters. Then, modulations are carried out like a standard dual six-phase inverter, either by carrier-based modulation or by space vector pulse-width modulation (SVPWM). Now by space vector theory, the output voltage vector $\bar{v}$ of the dual inverter can be expressed as the sum of the voltage vectors $\bar{v}_{H}$ and $\bar{v}_{L}$ by the single six-phase inverters $H$ and $L$, as given below [21, 23-25]:

$$
\bar{v}=\bar{v}_{H}+\bar{v}_{L}
$$

If the six-phase windings are split into standard two three-phase windings then Eq. 7 by considering Eq. 3 then the modulating vectors can represent as below:

$$
\begin{aligned}
& \bar{v}_{H}=\bar{v}_{H}^{(1)}+\bar{v}_{H}^{(2)} \\
& \bar{v}_{L}=\bar{v}_{L}^{(1)}+\bar{v}_{L}^{(2)}
\end{aligned}
$$

By considering Eq. 4, then Eq. 8 for single six-phase inverter $\mathrm{H}$ can be expressed as:

$$
\begin{gathered}
\bar{v}_{H}^{(1)}=\frac{1}{3} V_{H}\left(S_{H 1}+S_{H 2} e^{j 2 \pi / 3}+S_{H 3} e^{j 4 \pi / 3}\right) \\
\bar{v}_{H}^{(2)}=\frac{1}{3} V_{H}\left(S_{H 4} \alpha+S_{H 5} \alpha e^{j 2 \pi / 3}+S_{H 6} \alpha e^{j 4 \pi / 3}\right) \\
\bar{v}_{H}^{(1)}=\frac{1}{3} V_{H}\left(S_{H 1}+S_{H 2} e^{j 2 \pi / 3}+S_{H 3} e^{j 4 \pi / 3}+S_{H 4} \alpha+S_{H 5} \alpha e^{j 2 \pi / 3}+S_{H 6} \alpha e^{j 4 \pi / 3}\right)
\end{gathered}
$$

Similar by considering Eq. 4, then Eq. 9 for single six-phase inverter L can be expressed as:

$$
\begin{gathered}
\bar{v}_{L}^{(1)}=-\frac{1}{3} V_{L}\left(S_{L 1}+S_{L 2} e^{j 2 \pi / 3}+S_{L 3} e^{j 4 \pi / 3}\right) \\
\bar{v}_{L}^{(2)}=-\frac{1}{3} V_{L}\left(S_{L 4} \alpha e^{j}+S_{L 5} \alpha e^{j 2 \pi / 3}+S_{L 6} \alpha e^{j 4 \pi / 3}\right) \\
\bar{v}_{L}^{(1)}=-\frac{1}{3} V_{L}\left(S_{L 1}+S_{L 2} e^{j 2 \pi / 3}+S_{L 3} e^{j 4 \pi / 3}+S_{L 4} \alpha+S_{L 5} \alpha e^{j 2 \pi / 3}+S_{L 6} \alpha e^{j 4 \pi / 3}\right)
\end{gathered}
$$

By substituting Eq. 11 and Eq. 13 in Eq. 7, therefore now the arbitrary modulating vector for dual threephase inverter can be expressed as:

$$
\begin{aligned}
\bar{v}= & \frac{1}{3} V_{H}\left(S_{H 1}+S_{H 2} e^{j 2 \pi / 3}+S_{H 3} e^{j 4 \pi / 3}+S_{H 4} \alpha+S_{H 5} \alpha e^{j 2 \pi / 3}+S_{H 6} \alpha e^{j 4 \pi / 3}\right)+ \\
& \frac{1}{3} V_{L}\left(S_{L 1}+S_{L 2} e^{j 2 \pi / 3}+S_{L 3} e^{j 4 \pi / 3}+S_{L 4} \alpha+S_{L 5} \alpha e^{j 2 \pi / 3}+S_{L 6} \alpha e^{j 4 \pi / 3}\right)
\end{aligned}
$$

To be noted switching states, $\left\{S_{H}, S_{H 1}, S_{H 2}, S_{H 3} S_{H 4}, S_{H 5}, S_{H 6}\right\},\left\{S_{L}, S_{L 1}, S_{L 2}, S_{L 3}, S_{L 4}, S_{L 5}, S_{L 6}\right\}=\{1\}$, $\{0\}$ of the inverter legs $\mathrm{H}$ and $\mathrm{L}$. If presumed no zero-sequence currents in the system then Eq. 14 can be 
rewritten as two separate six-phase VSI, therefore potential difference across the open-windings as below [21, 23-25]:

$$
\left[\begin{array}{l}
v_{a} \\
v_{b} \\
v_{c} \\
v_{d} \\
v_{e} \\
v_{f}
\end{array}\right]=\frac{1}{3}\left[\begin{array}{cccccc}
1 & -1 / 2 & -1 & \sqrt{3} / 2 & -\sqrt{3} / 2 & 0 \\
0 & \sqrt{3} / 2 & -\sqrt{3} / 2 & 1 / 2 & 1 / 2 & -1 \\
1 & -1 / 2 & -1 / 2 & -\sqrt{3} / 2 & \sqrt{3} / 2 & 0 \\
0 & -\sqrt{3} / 2 & \sqrt{3} / 2 & 1 / 2 & 1 / 2 & -1 \\
1 & 1 & 1 & 0 & 0 & 0 \\
0 & 0 & 0 & 1 & 1 & 2
\end{array}\right]\left[\begin{array}{c}
v_{H 1} \\
v_{H 2} \\
v_{H 3} \\
v_{H 4} \\
v_{H 5} \\
v_{H 6}
\end{array}\right]-\frac{1}{3}\left[\begin{array}{cccccc}
1 & -1 / 2 & -1 & \sqrt{3} / 2 & -\sqrt{3} / 2 & 0 \\
0 & \sqrt{3} / 2 & -\sqrt{3} / 2 & 1 / 2 & 1 / 2 & -1 \\
1 & -1 / 2 & -1 / 2 & -\sqrt{3} / 2 & \sqrt{3} / 2 & 0 \\
0 & -\sqrt{3} / 2 & \sqrt{3} / 2 & 1 / 2 & 1 / 2 & -1 \\
1 & 1 & 1 & 0 & 0 & 0 \\
0 & 0 & 0 & 1 & 1 & 2
\end{array}\right]\left[\begin{array}{c}
v_{L 1} \\
v_{L 2} \\
v_{L 3} \\
v_{L 4} \\
v_{L 5} \\
v_{L 6}
\end{array}\right]
$$

For preliminary investigation, the analysis on the proposed converter are performed with single carrier based 5-level modulation is adapted in this paper. The modulating reference signals are compared against the standard triangular carrier to provide maximum utilization of DC buses and the ability to generate multilevel operation. Extension can be performed with the power sharing regulation in symmetrical /asymmetrical conditions can be performed between the two DC sources of the inverters $\mathrm{H}$ and L. The single carrier (MSCFM) modulation for inverter $\mathrm{H}$, generate 5-level across the leg-phase ' $a$ ' is shown in Fig. 2 and the same strategy is applied to all other leg-phases (c, d, e, f, g) of inverter H, keeping the proper phase-shift as shown by Fig. 1between reference modulating signals. To be noted, for phase A, switch $S_{H a}$ and $S_{L a}$ to be modulated throughout the fundamental cycle, i.e. swaps between

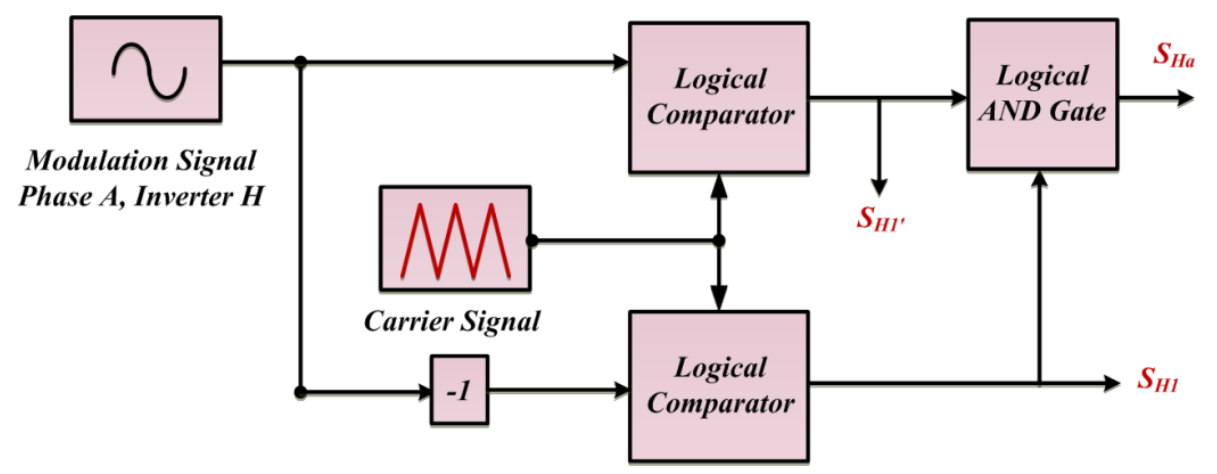

Fig. 2. Simplified multilevel modulation scheme with one carrier for phase A of inverter $\mathrm{H}$.

$\{1,0\}$ with switching period. Switch $S_{H I}$ has to be modulated half of the fundamental period (first-half) $\{1\}$ and retains $\{0\}$ second half and applicable reverse to the switch $S_{L I}$. To be noted, the same strategy is applied to other phases ' $b$ ' and ' $c$ ' to generate a five-level outputs. Correspondingly, the switch pattern of the proposed 5-level modulation for inverter $\mathrm{H}$ and $\mathrm{L}$ is shown in the Fig. 3 for modulation index of 0.8 .

\section{Simulation Results and Discussion}

Table I: Simulation parameters of dual three-phase multilevel inverter

\begin{tabular}{ll|l}
\hline DC Bus & $\left(V_{H}, V_{L}\right)$ & $=200 \mathrm{Volts}$ \\
\hline Load Resistances & $R$ & $=8 \Omega$ \\
\hline Load Inductances & $L$ & $=10 \mathrm{mH}$ \\
\hline Fundamental Frequency & $F$ & $=50 \mathrm{~Hz}$ \\
\hline Switching Frequency & $F_{S}$ & $=5 \mathrm{KHz}$ \\
\hline Capacitors & $V_{C}$ & $=2200 \mu \mathrm{F}$ \\
\hline
\end{tabular}

Table I elaborates the parameters taken for testing under working conditions. To verify the effectiveness of the proposed multiphase-multilevel converter, the complete AC drive system 


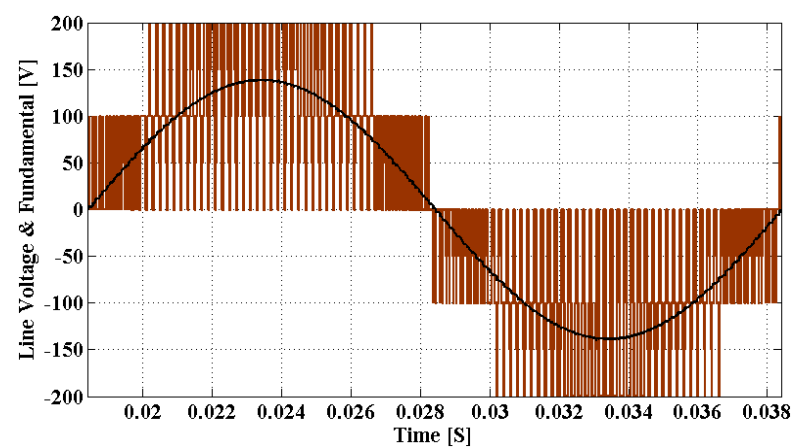

(A)

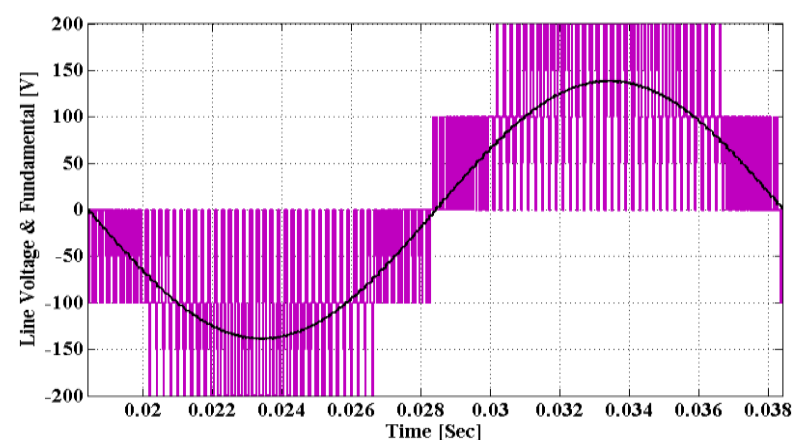

(B)

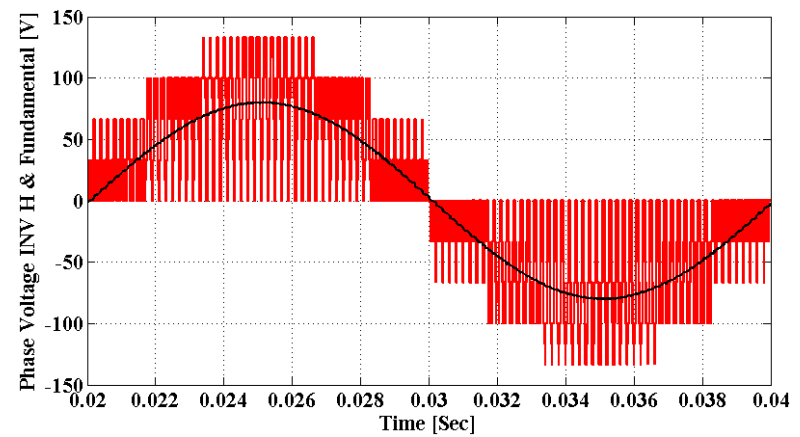

(C)

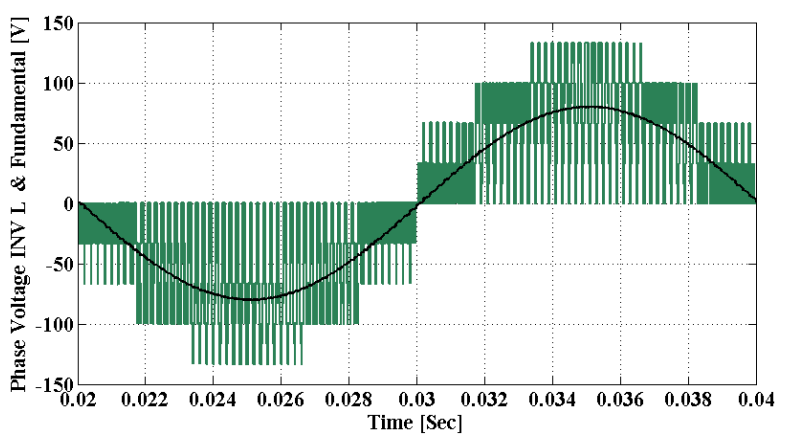

(D)

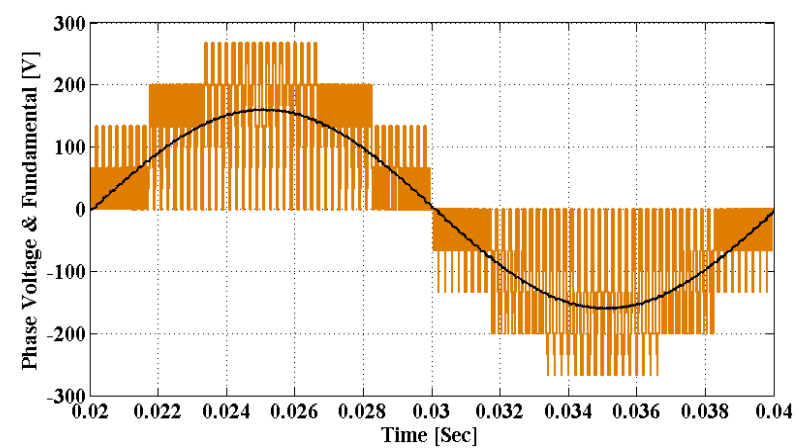

(E)

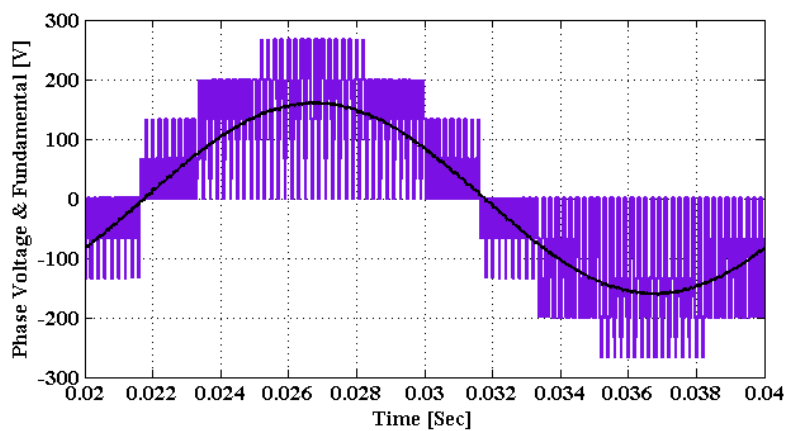

(F)

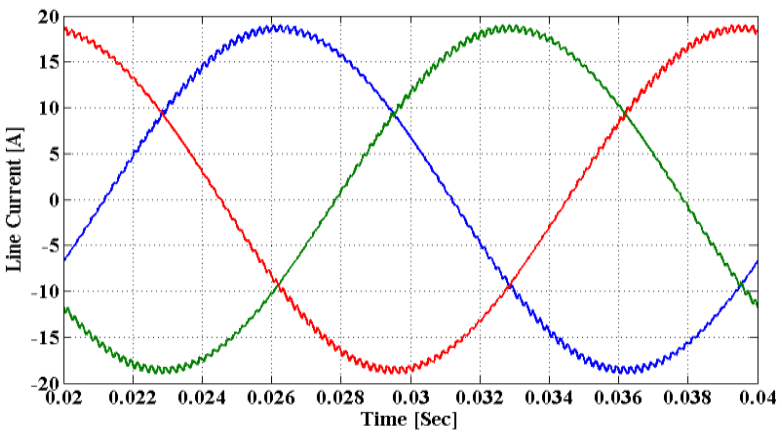

(G)

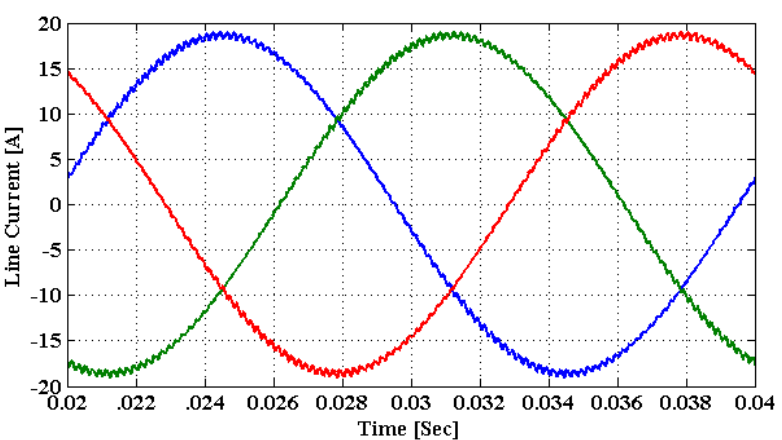

(H)

Fig. 3. Numerical simulation behavior of the proposed dual asymmetrical six-phase multilevel inverter and modulation index of inverter $V_{H}=V_{L}=0.8$ for balanced operation. (A) Line-line voltage of inverter $\mathrm{H}$, (B) line-line voltage of inverter $\mathrm{L}$. (C) and (D) Artificially measured first-phase voltage of inverter $\mathrm{H}\{1\}$, and inverter $\mathrm{L}$ $\{2\}$. (E) and (F) First-phase voltage across the open-winding $\{1\}$ and the open-winding $\{2\}$. $(\mathrm{G})$ and $(\mathrm{H})$ Threephase currents of the open-windings $\{1\}$ and open-windings $\{2\}$. Voltages are depicted with its corresponding time averaged fundamental components. 


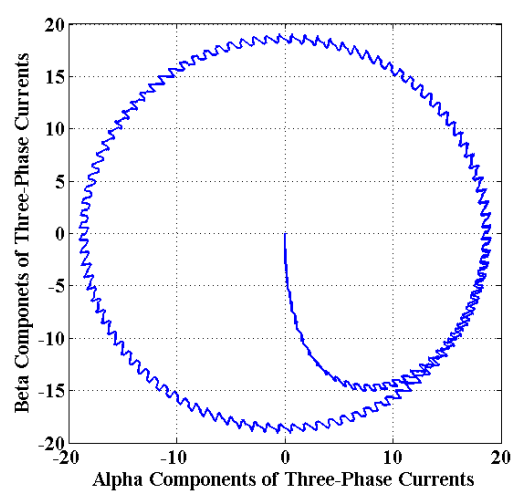

$d_{1}-q_{1}$ first sub-space.

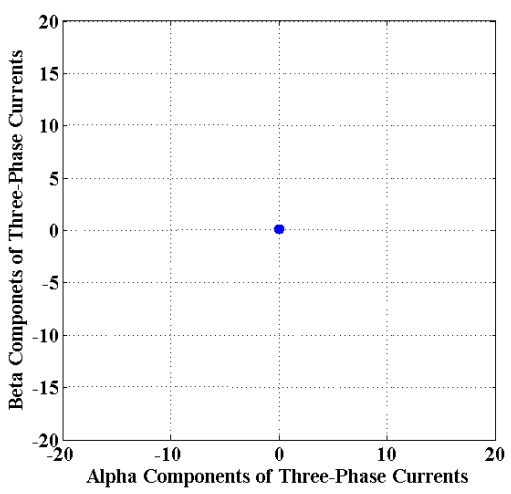

$d_{5}-q_{5}$ third sub-space.

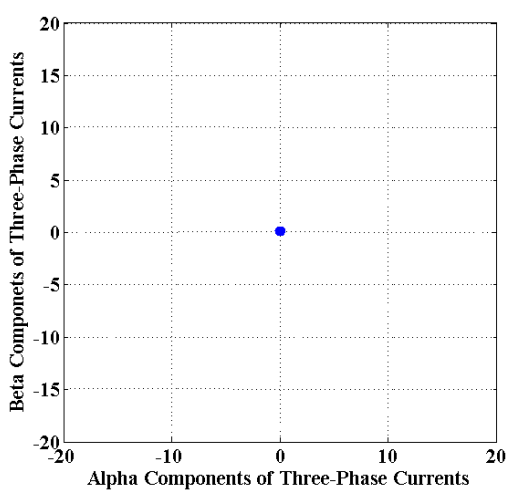

$d_{3}-q_{3}$ fifth sub-space.

Fig. 4. Trajectories of six-phase currents in sub-spaces of $\alpha-\beta$ rotating planes first sub-space (left), fifth sub-space (middle), and third sub-space (right).

numerically developed by means of the Matlab/PLECS simulation software package. The test conducted under the balanced conditions by fixing modulation index of inverter $\mathrm{H}$ and $\mathrm{L}$ to 0.8 and overall modulation index of six-phase inverter is 0.8 .

Fig. 3 shows the complete simulation behavior of the system under symmetrical operation. Where, Fig. 3(A) and Fig. 3(B) are the generated line-line voltage of inverter $\mathrm{H}$ and inverter $\mathrm{L}$ with its time scale averaged fundamental components. It is confirmed by the results that each VSIs are modulated at 5level of the developed modified single carrier five-level modulation (MSCFM) algorithm and proves that $\mathrm{H}$ and $\mathrm{L}$ are out of phase with respect to each other. Fig. 3(C) and Fig. 3(D) are the artificially measured phase ' $\mathrm{A}$ ' voltage of inverter $\mathrm{H}$ and $\mathrm{L}$ with its time scale averaged fundamental components. It is confirmed from the results that, inverter $\mathrm{H}$ and $\mathrm{L}$ generated 7-level of stepped wave which is actually predicted and generates fundamental component in agreement to Eq. 11 and Eq. 13. Further, it is verified that the fundamental components of the phase voltages generated by inverter $\mathrm{H}$ and $\mathrm{L}$ are of same amplitudes and confirms the balanced smooth operation (modulation index $=0.8$ )

Fig. 3(E) and Fig. 3(F) are the generated phase voltage of the open-winding phase 'a' $\{1\}$ and phase 'd' $\{2\}$ along with its time scale averaged fundamental component. First, it confirms that the voltages generated are 7-levels and obtained amplitude is the vector addition of phase voltages of inverter $\mathrm{H}$ and L. Second, it is observed two phase voltages are arbitrarily phase shifted by $30^{\circ}$, which is expected and generated fundamental confirms according to Eq. 14 (modulation index $=0.8$ ). Correspondingly, sixphase open-winding currents are shown in Fig. 4(G) (first three-phase $\{1\}$ ) and Fig. 3(H) (second threephase $\{2\})$. It is confirmed that generated currents are sinusoidal in nature and equally balanced in amplitude with proper phase shifts of $30^{\circ}$ between windings $\{1\}$ and $\{2\}$ could be clearly observed. Finally, this preliminary test confirms the satisfactory behavior of the multiphase-multilevel inverter performance under the balanced condition and in agreement with theoretical background. Finally, the trajectories of the six-phase currents are represented in alpha-beta $(\alpha-\beta)$ rotating planes are shown in Fig. 4. As predicted, in the case of the total electrical power is equally shared among two VSIs ( $\mathrm{H}$ and L), rotating component moves along a circular trajectory (at constant frequency) as shown by Fig. 4(left). Hence, confirming sinusoidally modulated PWM strategy for both VSIs H and L throughout the propagation period. It is observed that the fifth sub-space and the third sub-space trajectories confirms that null as given by Fig. 4(middle) and Fig. 4(left), further confirms the balanced operation of the converter.

\section{Conclusion}

A new multiphase-multilevel inverter with open-winding configuration for medium power (lowvoltage/high-current) and 'More-Electric Aircraft' applications are presented in this article. Also, proposed an original modified single carrier five-level modulation (MSCFM) algorithm ensures two six- 
phase VSIs ( $\mathrm{H}$ and $\mathrm{L}$ ) generates 5-level multi-stepped waveforms as outputs. Numerical simulation results are provided and shown suppressed lower order harmonics in the outputs with balanced power operation is observed. Proposed topology can be effectively utilized in batteries or fuel-cells fed system under asymmetrical conditions of two DC sources ( $\mathrm{H}$ and L) without affecting its multilevel operation, when subjected to $80 \%$ minimal DC bus utilization. Still investigation kept under developments to frame a proper multilevel (5-level) PWM generation based on the carrier based as well as space vector modulation methods for future publication works.

\section{References}

[1] E. Levi, "Multiphase electric machines for variable-speed applica־tions," IEEE Trans. Ind. Electron., vol. 55, no. 5, pp. 1893-1909, May 2008.

[2] E. Levi, R. Bojoi, F. Profumo, H.A. Toliyat, S. Williamson, "Multi-phase induction motor drives - a technology status review,” IET Electr. Power Appl., vol. 1, no.4, pp. 489-516, July 2007.

[3] G. Grandi, P. Sanjeevikumar, D. Ostojic, C. Rossi, "Quad-inverter configuration for multi-phase multi-level ac motor drives", Conf. Proc., Intl. Conf. Computational Technologies in Elect. and Electron. Engg., IEEESIBIRCON'10, Irkutsk Listvyanka (Russia), pp. 631-638, 11-15 Jul. 2010.

[4] G. Grandi, P. Sanjeevikumar, Y. Gritli, F. Filippetti, "Fault-tolerant control strategies for quad-inverter induction motor drives with one failed inverter", Conf. Proc. IEEE 20th Intl. Conf. on Electrical Machines, IEEE-ICEM'12, Marseille (France), pp. 957-964, 2-5 Sept. 2012.

[5] G.K.Singh, K.Nam, S.K.Lim, "A simple indirect field-oriented control scheme for multiphase induction machine", IEEE Trans. on Ind. Electron., vol. 52, no. 4, pp. 1177-1184, 2005.

[6] P.Sanjeevikumar, G.Grandi, F.Blaabjerg, Joseph Olorunfemi Ojo, Patrick Wheeler, "Power Sharing Algorithm for Vector Controlled Six-Phase AC Motor with Four Customary Three-Phase Voltage Source Inverter Drive”, Engg. Science and Tech; An Intl. J. (JESTECH), Elsevier Pub., vol. 16, no. 3, pp. 405-415, 11 Feb. 2015.

[7] A.Tani, M.Mengoni, L. Zarri, G.Serra, D.Casadei, "Control of multi-phase induction motors with an odd number of phases under open circuit faults", IEEE Trans. on Power Electronics, vol. 27, no. 2, pp. 565-577, 2012.

[8] P.Sanjeevikumar, G.Grandi, F.Blaabjerg, Patrick Wheeler, Olorunfemi Ojo, "Analysis and Implementation of Power Management and Control Strategy for Six-Phase Multilevel AC Drive System in Fault Condition", Engg. Science and Tech; An Intl. J. (JESTECH), Elsevier Pub., 13 Jul. 2015. Doi: 10.1016/j.jestch. 2015.07.007

[9] G. Grandi, P. Sanjeevikumar, Y. Gritli, F. Filippetti, "Experimental investigation of fault-tolerant control strategies for quad-inverter converters", Conf. Proc. IEEE Intl. Conf. on Electrical System for Aircraft, Railway and Ship Propulsion, IEEE-ESARS'12, Bologna (Italy), pp. 1-8, 16-18 Oct. 2012.

[10] G. Grandi, P. Sanjeevikumar, D. Casadei, "Preliminary hardware implementation of a six-phase quadinverter induction motor drive", Conf. Proc. The 14th European Conf. on Power Electron. and Appl., IEEEEPE'11, Birmingham (United Kingdom), pp. 1-9, 30 Aug.-1 Sept. 2011.

[11] W. Cao, B.C. Mecrow, G.J. Atkinson, J.W. Bennett, D.J. Atkinson, "Overview of electric motor technologies used for More-Electric Aircraft (MEA)", IEEE Trans. on Ind. Electron., vol. 59, no. 9, pp. 3523-3531, Sept. 2012.

[12] F. Scuiller, J.F. Charpentier, E. Semail, "Multi-star multi-phase winding for a high power naval propulsion machine with low ripple torques and high fault tolerant ability," Proc. of Vehicle Power and Propulsion Conference, Lille, France, pp. 1-5, 1-3 Sept. 2010.

[13] A. Cavagnino, Zijian Li, A. Tenconi, S. Vaschetto, "Integrated generator for More Electric Engine: design and testing of a scaled size prototype," IEEE Conf. Proc. of ECCE 2012, Raleigh, NC, USA, pp. 542-549, 15-20 Sept. 2012.

[14] Y.Zhao, T.A.Lipo, "Space vector PWM control of dual three-phase induction machine using vector space decomposition", IEEE Trans. on Ind. Appl., vol. 31, no. 5, pp. 1100-1109, 1995.

[15] R.Bojoi, F.Farina, F.Profumo, A.Tenconi, "Dual three-phase induction machine drives control— A survey", IEE J. Trans. on Ind. Appl., vol. 126, no. 4, 2006.

[16] R.Bojoi, M.Lazzari, RProfumo, A.Tenconi, "Digital field oriented control of dual three-phase induction motor drives", IEEE Trans. on Ind. Appls, vol. 39, pp. 75-760, 2005.

[17] R.Bojoi, F.Farina, G.Griva, F.Profumo, A.Tenconi, "Direct torque control for dual three-phase induction drives", IEEE Trans. on Ind. Appl., vol. 41, no. 6, pp. 1627-1636, 2005.

[18] Feng Gao, P.Chiang Loh, F.Blaabjerg,"Dual Z-Source Inverter With Three-Level Reduced Common-Mode Switching", IEEE Trans. on Ind. Appl., vol. 43, no. 6, pp. 1597-1608, Nov. 2007. 
[19] S.Chowdhury, Patrick Wheeler, Chris Gerada, S. Lopez Arevalo, "A dual inverter for an open end winding induction motor drive without an isolation transformer", Conf. Proc. IEEE Applied Power Electronics Conference and Exposition, IEEE-APEC'15, Charlotte, NC, USA, pp. 283-289, 15-19 March 2015.

[20] G.Grandi, C.Rossi, D.Ostojic, D.Casadei, "A new multilevel conversion structure for grid-connected PV applications", IEEE Trans. on Ind. Electron., vol. 56, no. 11, pp. 416-4426, 2009.

[21] P.Sanjeevikumar, F.Blaabjerg, Patrick Wheeler, Olorunfemi Ojo, "Three-phase multilevel inverter configuration for open-winding high power application", Conf. Proc., The 6th IEEE Intl. Symp. on Power Electron. for Distributed Generation Systems, IEEE-PEDG'15, Aachen (Germany), 22-25 June 2015.

[22] F.Blaabjerg, M.M.Pecht, "Robust Design and Reliability of Power Electronics", IEEE Trans. on Power Electron., vol. 30, no. 5, pp. 2373-2374, 2015.

[23] P.Sanjeevikumar, F.Blaabjerg, Patrick Wheeler, Olorunfemi Ojo, Kiran P. Maroti, "A Novel Double QuadInverter Configuration for Multilevel Twelve-Phase Open- Winding Converter", Conf. Proc. of 7th IEEE Intl. Conf. on Power System, IEEE-ICPS'16, Indian Institute of Technology (IIT-Delhi), Delhi (India), 4-6 Mar. 2016.

[24] P.Sanjeevikumar, F.Blaabjerg, Patrick Wheeler, Kyo-Beum Lee, S.B. Mahajan, " Five-Phase Five-Level Open-Winding/Star-Winding Inverter Drive For Low-Voltage/ High-Current Applications", Conf. Prof. of IEEE International Transportation Electrification Conf. and Expo, Asia-Pacific, (IEEE-ITEC'16), Busan (Korea). 1-4 Jun. 2016.

[25] P.Sanjeevikumar, F.Blaabjerg, Patrick Wheeler, Raghav Khanna, S.B. Mahajan, "Optimized Carrier Based Five-Level Generated Modified Dual Three-Phase Open- Winding Inverter For Medium Power Application", Conf. Prof. of IEEE International Transportation Electrification Conf. and Expo, Asia-Pacific, (IEEEITEC'16), Busan (Korea). 1-4 Jun. 2016. 